\title{
Study and Experiment on a Wheat Precision Seeding Robot
}

\author{
Lin Haibo, ${ }^{1}$ Dong Shuliang, ${ }^{2}$ Liu Zunmin, ${ }^{1}$ and Yi Chuijie ${ }^{3}$ \\ ${ }^{1}$ College of Mechanical Engineering, Qingdao Technological University, Qingdao 266520, China \\ ${ }^{2}$ School of Mechanical Engineering, Harbin Institute of Technology, Harbin 150001, China \\ ${ }^{3}$ Environmental Protection Bureau of Shandong Province, Jinan 250101, China \\ Correspondence should be addressed to Lin Haibo; haibolin76@163.com
}

Received 29 April 2015; Accepted 1 November 2015

Academic Editor: Yangmin Li

Copyright (C) 2015 Lin Haibo et al. This is an open access article distributed under the Creative Commons Attribution License, which permits unrestricted use, distribution, and reproduction in any medium, provided the original work is properly cited.

\begin{abstract}
The wheat precision seeding technology provided an advanced agricultural support for the high yield of wheat. But the lack of effective agricultural machine made this technique difficult to apply widely. In this paper a wheel mobile robot to achieve the wheat precision seeding technology was designed. The kinematic model of the robot was built and simulated. And experimental study was taken under different operating conditions. Because of multiple effort factors, a quadratic orthogonal rotation combination design method was applied in the experiments, identifying the main factors by analysis. Then the field test was carried out according to the main factors. The experiment results showed that the qualified rates of seeding exceed $93 \%$ in different sowing speed. That reached the agronomic requirements of wheat precision seeding.
\end{abstract}

\section{Introduction}

With the development of agriculture in China, the traditional intensive and meticulous farming had been unable to meet the requirements of current agriculture and agronomy development. Using agricultural machinery instead of the traditional manpower had become a major trend in the world $[1,2]$. And the agricultural robot had become an important target in research and development of agricultural machinery engineering $[3,4]$. In agricultural robotics research, Japan, the United States, and other countries were in the lead $[5,6]$. In China it started in these years, and there was a certain gap in technology comparing with the developed countries $[7,8]$.

Wheat is one of major food crops in China. China's wheat acreage was 24 million hectares in 2013. Increase of wheat production was of great significance for China's food security. Academician Songlie from Shandong Agricultural University proposed the wheat precision seeding agronomic techniques to improve wheat yield. Using Lumai-5 as experimental wheat seed, the experiments results showed that the yield of the precision seeding techniques was greater by $7.5 \%$ to $22.3 \%$ than that of the traditional seeding techniques [9]. However, due to the special characteristics of the wheat seed grain geometry, now the mechanization for the wheat precision seeding techniques was still in research stage. Automatic agricultural vehicles had received attentions from the 1920s [10]. Especially in the recent 20 years, with the development of computer and sensor technologies, numerous researches on this subject, particularly agricultural robots, had been reported [11-15]. In this paper, a wheel mobile robot was designed and developed for the wheat precision seeding. A kinematic model was built for the four-wheel drive robot, and some experiments were taken using this machine. It provided a reference for the design and product of wheat precision seeding robot.

\section{Design of the Precision Seeding Robot}

According to the working environment of the robot and the agronomic requirements of the wheat precision seeding techniques, this robot was designed with four-wheel drive, the drive system using servo motor, and the steering system using stepper motor [16]. To ensure the robot's load-bearing capacity and robustness, the frame was welded by rectangular steel together, seen in Figure 1. Figure 2 was the system block diagram of the wheat precision seeding robot. The robot was 


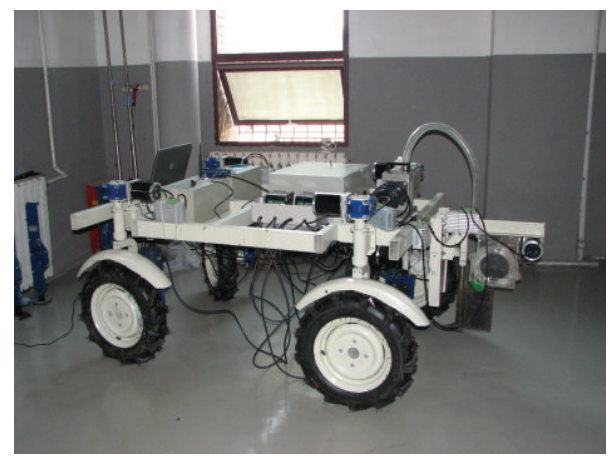

FIGURE 1: Wheat precision seeding robot.

mainly divided into three parts: the robot mobile body, the control system, and the sensor system. And, the robot mobile body was divided into the mobile platform and the precision seeding mechanism. The control system was the core of the robot, seen in Figure 2. It could process the sensor signal and the information received in the working time. By adjusting the coherent drive motors, the control system could precisely control the movement of the robot, the picking up and seed of the wheat, and the adjustment of the pressure of the vacuum chamber, realizing the agronomic requirements of the wheat precision seeding.

\section{Kinematic Model and Simulation}

For the mobile robot, the model reflected the relationship between the state variables and control parameters of the robot. So, It was essential to build the model to design an effective tracing control law for small error or no error robot trajectory tracking. In this paper, the precision seeding robot's platform was designed with 4 -wheel drive and 4wheel steering. Rotation and steering of the four wheels are controlled independently, there were four servomotors to control each wheel for rotation, and there were also four step motors to steer. A central controller coordinated the eight motors to work well together. Theoretically, the fourwheel steering scheme has all the degrees of freedom in the plane [17]. But, there were many forms that were not practical in actual application. Figure 3 shows some basic operation mode. Considering the characteristics and the actual situation of the working in the field, mode (c) was selected in the design of the wheat precision seeding robot.

Two assumptions were made in this paper for the kinematic model of the robot: (1) the platform of the robot was considered as a rigid body and the wheel was considered as a rigid wheel; it was that the elastic deformation of the wheel and the ground was ignored; (2) the robot did not consider the vertical and pitching motion, excluding the impact of roll.

In this paper, we discussed the kinematic model of mobile robot when front and rear wheels are steering in the opposite direction, showing in Figure 3(c). Through analyzing the four-wheel opposite steering mode, there were some certain relationships in the steering angle between the rear wheels and the front wheels and the speed between the left wheels and the right wheels.

Figure 4 was the schematic diagram of four-wheel steering mode. $\mathrm{O}_{3}$ was the instantaneous center of the mobile robot platform; $P X^{\prime} Y^{\prime}$ was the coordinate system of the mobile robot; $\mathrm{O}_{2}$ is the rear wheels' axis center; $\mathrm{O}_{1}$ was an intersection point of the line through the point $\mathrm{O}_{3}$ perpendicular to the body axis and the extended line of the wheels axis; $P$ is the reference point for precision seeding meter. $\phi_{\mathrm{fl}}$ was the steering angle of the front-left wheel; $\phi_{\mathrm{bl}}$ was the steering angle of the rear-left wheel; $v_{\mathrm{fl}}$ was the speed of the front-left wheel; $v_{\mathrm{bl}}$ was the velocity of the rear-left wheel; $v_{p}$ was the velocity of the reference point $P$; $v_{o_{3}}$ was the velocity of $\mathrm{O}_{3} ; x_{0}$ was the distance between $\mathrm{O}_{3}$ and the front wheels axis.

Given $\phi_{\mathrm{fl}}$, the steering angle of front-left wheel, and $\phi_{\mathrm{bl}}$, the steering angle of rear-left wheel, the following relationship could be obtained from the triangle:

$$
x_{0}=\frac{2 l \cdot \tan \phi_{\mathrm{fl}}}{\tan \phi_{\mathrm{fl}}+\tan \phi_{\mathrm{bl}}} .
$$

By the velocity of rear-left wheel, the robot's angular velocity around the instantaneous center could be obtained as

$$
\omega=\frac{v_{\mathrm{fl}} \cdot \sin \phi_{\mathrm{fl}}}{x_{0}}=\frac{v_{\mathrm{fl}}}{2 l}\left(\sin \phi_{\mathrm{fl}}+\cos \phi_{\mathrm{fl}} \cdot \tan \phi_{\mathrm{bl}}\right) .
$$

As $O_{1} O_{3}=x_{0} / \tan \phi_{\mathrm{fl}}+b$, the velocity of $\mathrm{O}_{3}$ was

$$
v_{o_{3}}=\omega \cdot O_{1} O_{3}=v_{\mathrm{fl}} \cdot \cos \phi_{\mathrm{fl}}+\frac{b}{x_{0}} \cdot v_{\mathrm{fl}} \cdot \sin \phi_{\mathrm{fl}} .
$$

The kinematic model of the system could be established with $\mathrm{O}_{3}$ for reference points as

$$
\begin{aligned}
& \dot{x}_{o_{3}}=\left(v_{\mathrm{fl}} \cdot \cos \phi_{\mathrm{fl}}+\frac{b}{x_{0}} \cdot v_{\mathrm{fl}} \cdot \sin \phi_{\mathrm{fl}}\right) \cdot \cos \theta, \\
& \dot{y}_{o_{3}}=\left(v_{\mathrm{fl}} \cdot \cos \phi_{\mathrm{fl}}+\frac{b}{x_{0}} \cdot v_{\mathrm{fl}} \cdot \sin \phi_{\mathrm{fl}}\right) \cdot \sin \theta, \\
& \dot{\theta}_{o_{3}}=\frac{v_{\mathrm{fl}} \cdot \sin \phi_{\mathrm{fl}}}{x_{0}} .
\end{aligned}
$$

From the relationship of points $\mathrm{O}_{3}$ and $P$, (5) could be derived:

$$
\begin{aligned}
& x_{p}=x_{o_{3}}-\left(m+2 l-x_{0}\right) \cdot \cos \theta \\
& y_{p}=y_{o_{3}}-\left(m+2 l-x_{0}\right) \cdot \sin \theta, \\
& \theta_{p}=\theta-\alpha .
\end{aligned}
$$

By taking derivation on both sides of (5), the kinematics model with $p$ for reference point was

$$
\begin{aligned}
& \dot{x}_{p}=v_{o_{3}} \cdot \cos \theta+\left(m+2 l-x_{0}\right) \cdot \sin \theta \cdot \omega, \\
& \dot{y}_{p}=v_{o_{3}} \cdot \sin \theta-\left(m+2 l-x_{0}\right) \cdot \cos \theta \cdot \omega, \\
& \dot{\theta}_{p}=\omega .
\end{aligned}
$$




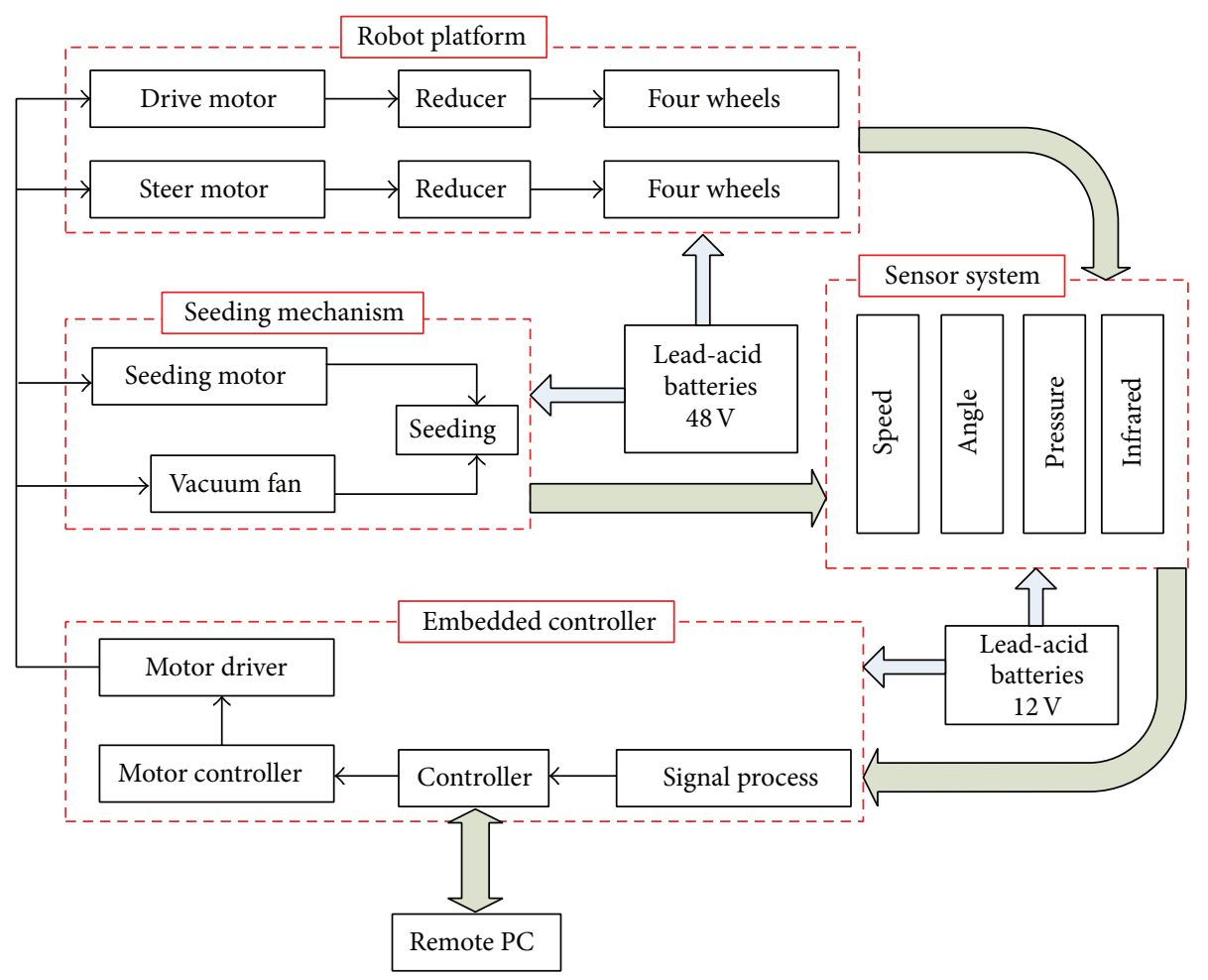

FigURE 2: System block diagram of the robot.

It was

$$
\left[\begin{array}{l}
\dot{x}_{p} \\
\dot{y}_{p} \\
\dot{\theta}_{p}
\end{array}\right]=\left[\begin{array}{cc}
\cos \theta & \left(m+2 l-x_{0}\right) \sin \theta \\
\sin \theta & -\left(m+2 l-x_{0}\right) \cos \theta \\
0 & 1
\end{array}\right] \cdot\left[\begin{array}{c}
v_{o_{3}} \\
\omega
\end{array}\right] .
$$

In (7), $v_{o_{3}}, x_{0}$, and $\omega$ could be obtained from $\phi_{\mathrm{fl}}$ and $\phi_{\mathrm{bl}}$. And the relationship of the left wheels and the right wheels was

$$
\begin{aligned}
\phi_{\mathrm{fr}} & =\arctan \frac{x_{0} \tan \phi_{\mathrm{fl}}}{x_{0}+2 b \tan \phi_{\mathrm{fl}}}, \\
\phi_{\mathrm{br}} & =\arctan \frac{\left(2 l-x_{0}\right) \tan \phi_{\mathrm{fl}}}{x_{0}+2 b \tan \phi_{\mathrm{fl}}} .
\end{aligned}
$$

From these equations, when $\phi_{\mathrm{bl}}=0$, the front wheel steering kinematic model of the robot could be obtained.

Based on the kinematic model, a trajectory tracking controller was built and simulation was taken on the control law. The error differential equation of the wheat precision seeding robot was

$$
\begin{aligned}
& \dot{x}_{e}=-k_{1} x_{e}+y_{e} \omega_{r}+k_{2} v_{r} y_{e}^{2}+k_{3} v_{r} y_{e} \sin \theta_{e}, \\
& \dot{y}_{e}=-x_{e} \omega_{r}-k_{2} v_{r} x_{e} y_{e}-k_{3} v_{r} x_{e} \sin \theta_{e}+v_{r} \sin \theta_{e}, \\
& \dot{\theta}_{e}=-k_{2} v_{r} y_{e}-k_{3} v_{r} \sin \theta_{e} .
\end{aligned}
$$

First, straight line trajectory tracking was simulated. Set the linear equation as follows:

$$
\begin{aligned}
& x(t)=t, \\
& y(t)=t+1 .
\end{aligned}
$$

In straight line motion, $\omega_{r}=0$, the velocity was constant, and set $v_{r}=1,\left[k_{1}, k_{2}, k_{3}\right]^{T}=[5,5,5]^{T}$. So the differential equation of the robot was as follows:

$$
\begin{aligned}
& \dot{x}_{e}=-5 x_{e}+5 y_{e}^{2}+5 y_{e} \sin \theta_{e}, \\
& \dot{y}_{e}=-5 x_{e} y_{e}-5 x_{e} \sin \theta_{e}+\sin \theta_{e}, \\
& \dot{\theta}_{e}=-5 y_{e}-5 \sin \theta_{e} .
\end{aligned}
$$

The initial location of the robot was $P(0)=[0,0,0]^{T}$, the initial location of the desired trajectory was $R(0)=$ $[0,1,-\pi / 4]^{T}$, and Figure 5 was the error curve of straight line tracking. Figure 6 was the actual movement of the robot tracking a straight line.

From the simulation, the errors of $x$ and $y$ and the angle became 0 after $3.5 \mathrm{~s}$. The actual path and expected path were overlapped after $3 \mathrm{~s}$.

Then, circular trajectory tracking was simulated. The circle equation was

$$
\begin{aligned}
& x(t)=\sin (2 \pi t), \\
& y(t)=\cos (2 \pi t), \\
& \theta(t)=2 \pi t .
\end{aligned}
$$




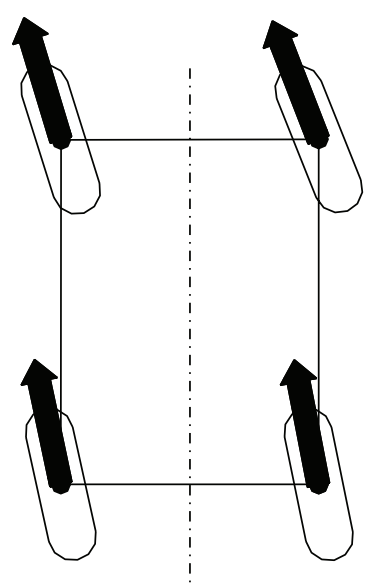

(a)

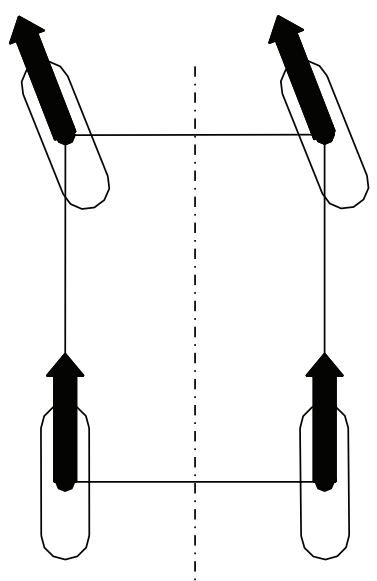

(b)

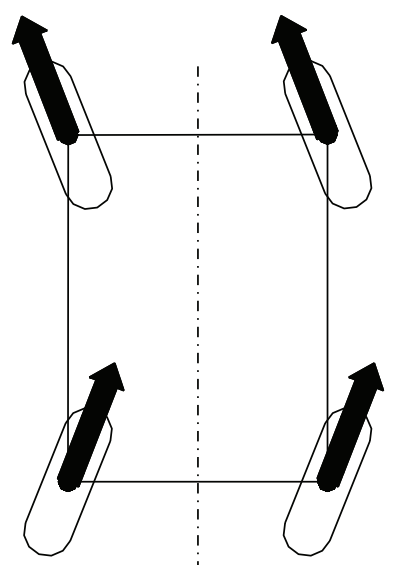

(c)

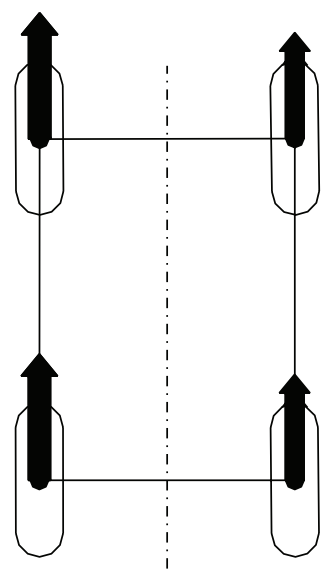

(d)

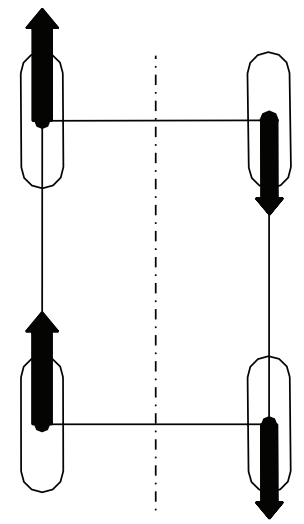

(e)

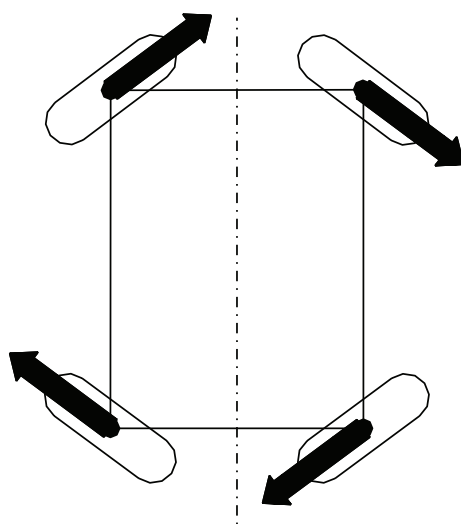

(f)

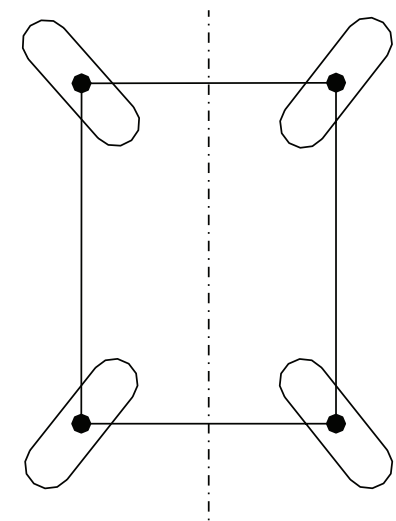

(g)

FIGURE 3: Some basic operation mode. (a) Four-wheel same direction steering, (b) front wheel steering, (c) four-wheel opposite steering, (d) differential speed mode, (e) slide steering mode, (f) zero radius steering mode, and (g) braking mode.

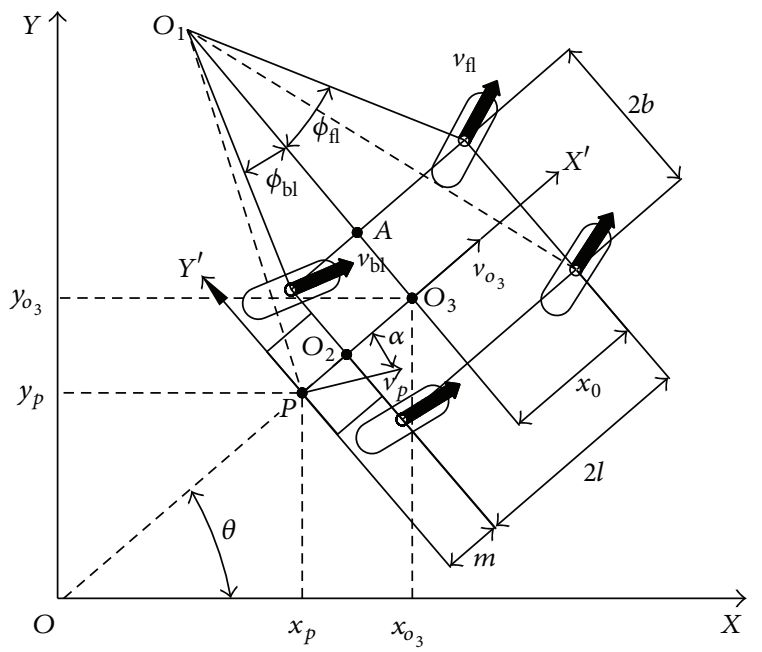

FiguRE 4: Schematic diagram of four-wheel steering mode.

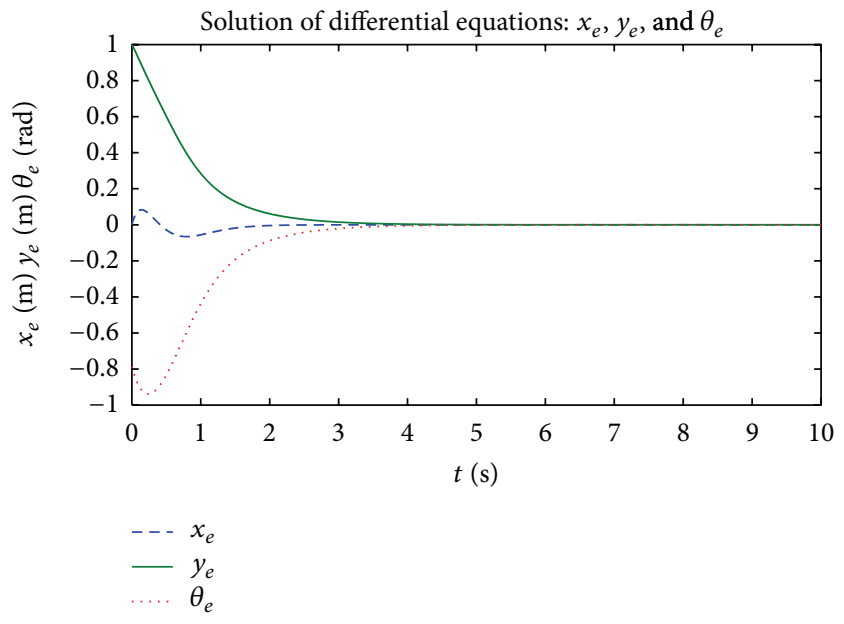

FIGURE 5: Diagram of error curve of straight line tracking.
The robot's initial position was $p(0)=(-0.5,0.5, \pi / 2)^{T}$ and the initial position of expected path was $R(0)=(0,1,0)^{T}$.
The expected linear velocity and angular velocity were $\left[v_{r}, \omega_{r}\right]^{T}=[\pi / 12, \pi / 6]^{T}$. The controller parameter was 


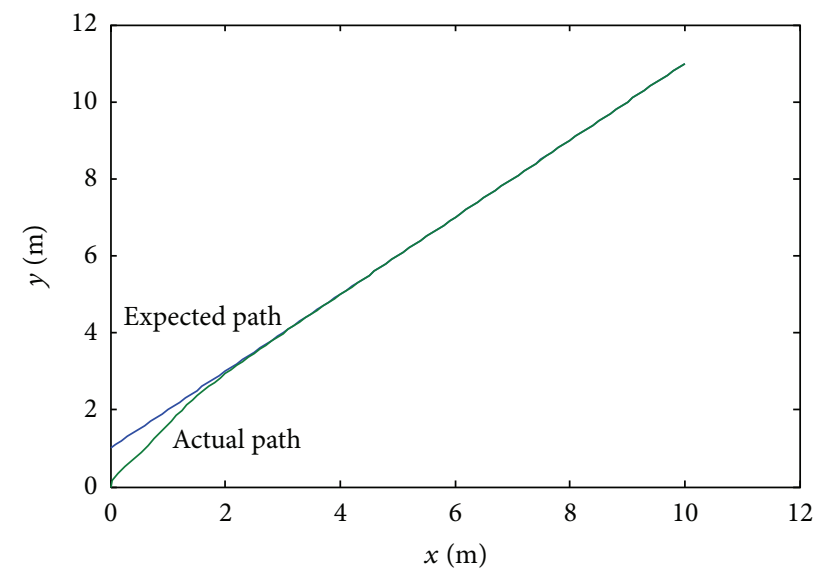

FIGURE 6: Diagram of the movement of straight line tracking.

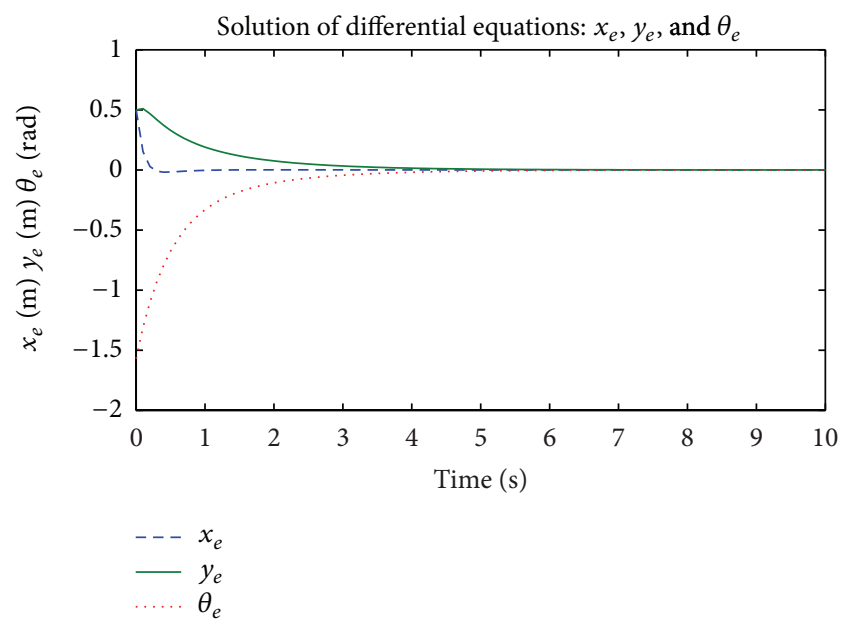

FIGURE 7: Diagram of error curve of circular tracking.

$\left[k_{1}, k_{2}, k_{3}\right]^{T}=[20,20,10]^{T}$. The differential equation for the location of the robot was as follows:

$$
\begin{aligned}
& \dot{x}_{e}=-20 x_{e}+\frac{\pi}{12} y_{e}+\frac{10 \pi}{3} y_{e}^{2}+\frac{5 \pi}{3} y_{e} \sin \theta_{e} \\
& \dot{y}_{e}=-\frac{\pi}{12} x_{e}-\frac{10 \pi}{3} x_{e} y_{e}-\frac{5 \pi}{3} x_{e} \sin \theta_{e}+\frac{\pi}{6} \sin \theta_{e}, \\
& \dot{\theta}_{e}=-\frac{10 \pi}{3} y_{e}-\frac{5 \pi}{3} \sin \theta_{e} .
\end{aligned}
$$

Figures 7 and 8 showed the result of simulation.

From the diagram, the errors of $x$ and $y$ and angle became 0 after $3 \mathrm{~s}$. In the movement diagram, the path turned 2 circles before the actual curve to coincide with expected path, so the error in $y$-axis should better be improved.

\section{Design of Seeding Experiments}

During the working, for the robot, the main factors affecting the quality of seeding were three: the pore size of planting tray, the pressure (negative) of vacuum chamber, and the speed of the planting tray [18]. The pressure of vacuum chamber and

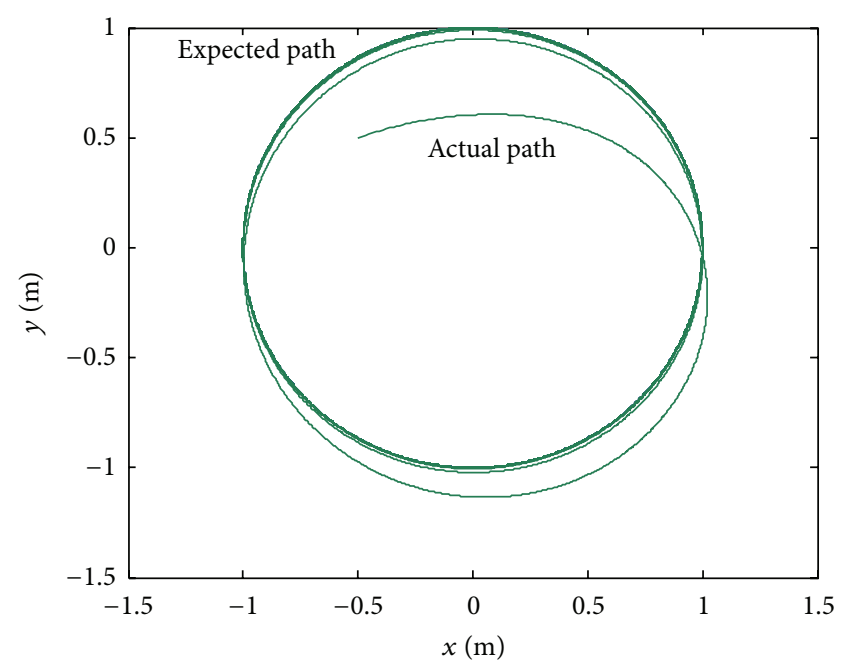

FIGURE 8: Diagram of the movement of circular tracking.

TABLE 1: Code variable design level and the value.

\begin{tabular}{cccccc}
\hline Level & $-r$ & -1 & 0 & 1 & $r$ \\
\hline Value & $x_{0 i}-\Delta_{i} \times r$ & $x_{0 i}-\Delta_{i}$ & $x_{0 i}$ & $x_{0 i}+\Delta_{i}$ & $x_{0 i}+\Delta_{i} \times r$ \\
\hline
\end{tabular}

the pore size of the planting tray had a direct impact on the leakage rate and reseeding rate. The smaller size needed the bigger pressure, and if the pore size was too small, it would cause the absorbing force which was too weak to pick up the seed, resulting in leakage phenomenon. If the pressure was too big, it would cause the increase of the reseeding. Meanwhile in the seeding process, if the speed of planting tray exceeded a certain limit, there was no adequate filling time, likely to cause serious leakage phenomenon [19-21].

Due to the fact that the impact of these factors on the qualified rate was not a simple linear relationship, the quadratic orthogonal rotation combination design method was taken in this paper to arrange the experiments. The regression analysis was used to analyze the connection between the factors and determine the relation of primary and secondary between them.

According to the quadratic orthogonal rotation combination design method, the test points were composed of 3 types of combination $[22,23]$; it was

$$
n=m_{c}+m_{r}+m_{0}
$$

And $m_{c}$ was the test number of factor point, $m_{r}$ was the test number of star point, and $m_{0}$ was the test number of zero level center point. The number of factors was 3, so all the test numbers were 23 .

According to the test and experience, the best combination of factors was selected as the zero level of the experiments, the pore size of the planting tray was $2.4 \mathrm{~mm}$, the speed of the planting tray was $30 \mathrm{r} / \mathrm{min}$, and the pressure of the vacuum chamber was $-2.3 \mathrm{kPa}$. The values and code table of each level of the 3 factors were determined according to the zero level, as shown in Tables 1 and 2. 
TABLE 2: Level code table of tests factors.

\begin{tabular}{lccc}
\hline $\begin{array}{l}\text { Level } \\
z_{j}\end{array}$ & $\begin{array}{c}\text { Pore size } \\
x_{1} / \mathrm{mm}\end{array}$ & $\begin{array}{c}\text { Speed } \\
x_{2} /(\mathrm{r} / \mathrm{min})\end{array}$ & $\begin{array}{c}\text { Pressure } \\
x_{3} / \mathrm{kPa}\end{array}$ \\
\hline-1.682 & 2.0 & 20 & -1.8 \\
-1 & 2.16 & 24 & -2.0 \\
0 & 2.4 & 30 & -2.3 \\
1 & 2.64 & 36 & -2.6 \\
1.682 & 2.8 & 40 & -2.8 \\
\hline
\end{tabular}

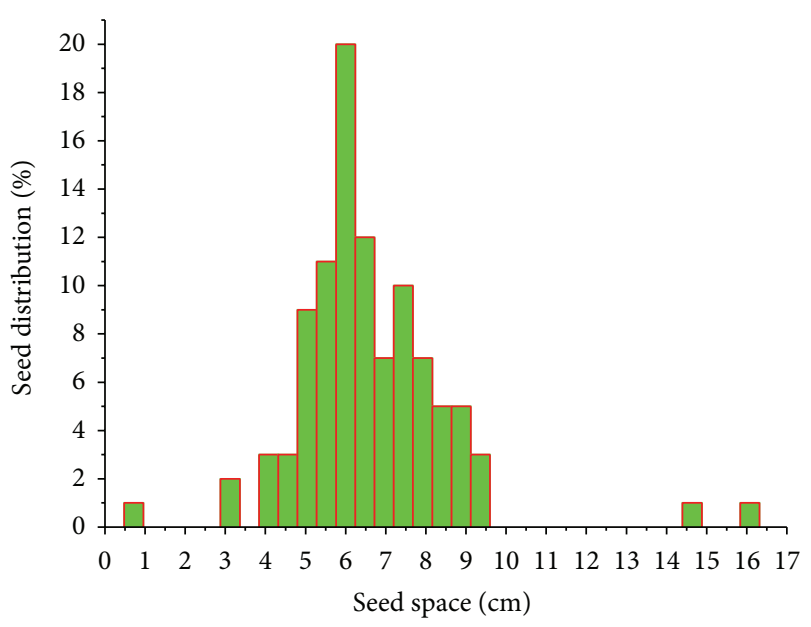

Figure 9: Statistical chart at $0.7 \mathrm{~m} / \mathrm{s}$.

Table 3 was the orthogonal rotation design structure matrix and calculation table of the seeding qualified rate.

Because the design factors were the function of the norms variable $z$ confirmed by a dimensionless linear coding, these $b_{i}$ among the first term regression coefficients and $b_{i}$ and the interaction terms were not relevant. Therefore, the affection to seeding qualified rate was directly judged by comparing the absolute values of the norms variable regression coefficient $b_{i}$. So the influence order within a certain range was $x_{2}>x_{3}>$ $x_{1}$. Among them, the speed $x_{2}$ was the biggest effect on the seeding performance, the pressure $x_{3}$ was less, and the pore size $x_{1}$ was the smallest.

Based on the above analysis, the conditions for the seeding experiments of the robot were listed in Table 4. The experiments were taken under different speeds to verify the performance of the robot.

\section{Result Analysis}

For the three speeds, 100 adjacent seed spaces as a sample were selected from each speed experiment. Tables 5-7 were the selected data at the speeds of $0.7 \mathrm{~m} / \mathrm{s}, 0.9 \mathrm{~m} / \mathrm{s}$, and $1.1 \mathrm{~m} / \mathrm{s}$. Figures 9-11 were the statistical chart of the measured seed space under each speed.

According to the standard GB/T6973-2005 (testing methods of single seed drills (precision drills)), the leakage was that the seed space was greater than 1.5 times the set distance.

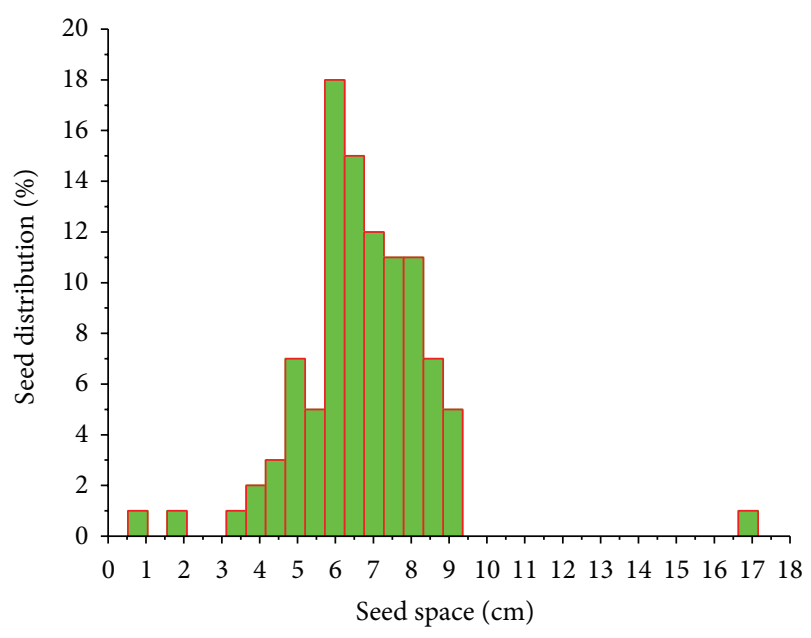

FIGURE 10: Statistical chart at $0.9 \mathrm{~m} / \mathrm{s}$.

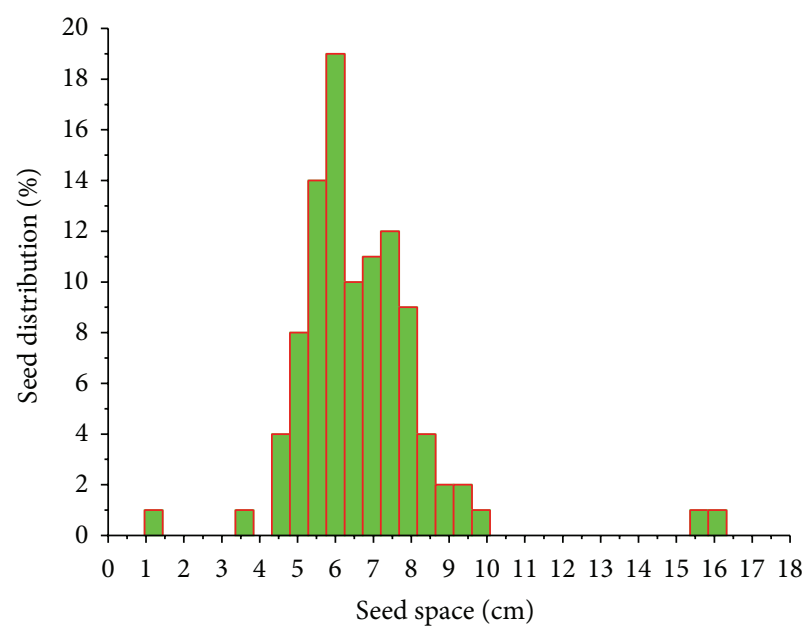

FIGURE 11: Statistical chart under $1.1 \mathrm{~m} / \mathrm{s}$.

And the reseed was that the seed space was smaller than 0.5 times the set distance. So, the seed space was divided into several ranges: $[0,0.5 x],(0.5 x, 1.5 x],(1.5 x, 2.5 x],(2.5 x, 3.5 x]$, and $(3.5 x,+\infty] ; x$ was the set seed space. Consider

$$
\begin{array}{ll}
n_{1}^{\prime}=\sum n_{i} \quad n_{i} \in(0,0.5 x], \\
n_{2}^{\prime}=\sum n_{i} \quad n_{i} \in(0.5 x, 1.5 x], \\
n_{3}^{\prime}=\sum n_{i} \quad n_{i} \in(1.5 x, 2.5 x], \\
n_{4}^{\prime}=\sum n_{i} \quad n_{i} \in(2.5 x, 3.5 x], \\
n_{5}^{\prime}=\sum n_{i} \quad n_{i} \in(3.5 x,+\infty], \\
N=n_{1}^{\prime}+n_{2}^{\prime}+n_{3}^{\prime}+n_{4}^{\prime}+n_{5}^{\prime} .
\end{array}
$$


TABLE 3: Orthogonal rotation design structure matrix and calculation.

\begin{tabular}{|c|c|c|c|c|c|c|c|c|c|c|c|}
\hline Number & $z_{0}$ & $z_{1}$ & $z_{2}$ & $z_{3}$ & $z_{1} z_{2}$ & $z_{1} z_{3}$ & $z_{2} z_{3}$ & $z_{1}^{\prime}$ & $z_{2}^{\prime}$ & $z_{3}^{\prime}$ & $y_{i}$ \\
\hline 1 & 1 & 1 & 1 & 1 & 1 & 1 & 1 & 0.406 & 0.406 & 0.406 & 85.780 \\
\hline 2 & 1 & 1 & 1 & -1 & 1 & -1 & -1 & 0.406 & 0.406 & 0.406 & 82.370 \\
\hline 3 & 1 & 1 & -1 & 1 & -1 & 1 & -1 & 0.406 & 0.406 & 0.406 & 94.650 \\
\hline 4 & 1 & 1 & -1 & -1 & -1 & -1 & 1 & 0.406 & 0.406 & 0.406 & 93.270 \\
\hline 5 & 1 & -1 & 1 & 1 & -1 & -1 & 1 & 0.406 & 0.406 & 0.406 & 87.560 \\
\hline 6 & 1 & -1 & 1 & -1 & -1 & 1 & -1 & 0.406 & 0.406 & 0.406 & 80.350 \\
\hline 7 & 1 & -1 & -1 & 1 & 1 & -1 & -1 & 0.406 & 0.406 & 0.406 & 93.420 \\
\hline 8 & 1 & -1 & -1 & -1 & 1 & 1 & 1 & 0.406 & 0.406 & 0.406 & 83.380 \\
\hline 9 & 1 & 1.682 & 0 & 0 & 0 & 0 & 0 & 2.234 & -0.594 & -0.594 & 92.830 \\
\hline 10 & 1 & -1.682 & 0 & 0 & 0 & 0 & 0 & 2.234 & -0.594 & -0.594 & 84.620 \\
\hline 11 & 1 & 0 & 1.682 & 0 & 0 & 0 & 0 & -0.594 & 2.234 & -0.594 & 85.220 \\
\hline 12 & 1 & 0 & -1.682 & 0 & 0 & 0 & 0 & -0.594 & 2.234 & -0.594 & 95.360 \\
\hline 13 & 1 & 0 & 0 & 1.682 & 0 & 0 & 0 & -0.594 & -0.594 & 2.234 & 93.830 \\
\hline 14 & 1 & 0 & 0 & -1.682 & 0 & 0 & 0 & -0.594 & -0.594 & 2.234 & 90.430 \\
\hline 15 & 1 & 0 & 0 & 0 & 0 & 0 & 0 & -0.594 & -0.594 & -0.594 & 94.600 \\
\hline 16 & 1 & 0 & 0 & 0 & 0 & 0 & 0 & -0.594 & -0.594 & -0.594 & 92.140 \\
\hline 17 & 1 & 0 & 0 & 0 & 0 & 0 & 0 & -0.594 & -0.594 & -0.594 & 90.230 \\
\hline 18 & 1 & 0 & 0 & 0 & 0 & 0 & 0 & -0.594 & -0.594 & -0.594 & 92.600 \\
\hline 19 & 1 & 0 & 0 & 0 & 0 & 0 & 0 & -0.594 & -0.594 & -0.594 & 95.120 \\
\hline 20 & 1 & 0 & 0 & 0 & 0 & 0 & 0 & -0.594 & -0.594 & -0.594 & 92.460 \\
\hline 21 & 1 & 0 & 0 & 0 & 0 & 0 & 0 & -0.594 & -0.594 & -0.594 & 94.340 \\
\hline 22 & 1 & 0 & 0 & 0 & 0 & 0 & 0 & -0.594 & -0.594 & -0.594 & 93.280 \\
\hline 23 & 1 & 0 & 0 & 0 & 0 & 0 & 0 & -0.594 & -0.594 & -0.594 & 95.640 \\
\hline$B_{i}=\sum z y$ & 2083.48 & 25.169 & -45.715 & 27.759 & -10.880 & -12.460 & -0.800 & -34.979 & -26.127 & -15.720 & \\
\hline$d_{i}=\sum z^{2}$ & 23.000 & 13.660 & 13.660 & 13.660 & 8.000 & 8.000 & 8.000 & 15.890 & 15.890 & 15.890 & \\
\hline$b_{i}=\frac{B_{i}}{d_{i}}$ & 90.586 & 1.843 & -3.347 & 2.032 & -1.360 & -1.558 & -0.100 & -2.201 & -1.644 & -0.989 & \\
\hline$S S_{i}=b_{i} B_{i}$ & & 46.376 & 152.995 & 56.409 & 14.797 & 19.406 & 0.080 & 76.998 & 42.959 & 15.552 & \\
\hline
\end{tabular}

TABLE 4: Experiment parameters list.

\begin{tabular}{lcc}
\hline Item & Value & Unit \\
\hline Pore size & 2.5 & $\mathrm{~mm}$ \\
Pressure & -2.4 & $\mathrm{kPa}$ \\
Seed space & 6 & $\mathrm{~cm}$ \\
Speed & $0.7,0.9,1.1$ & $\mathrm{~m} / \mathrm{s}$ \\
\hline
\end{tabular}

Define the leakage number $n_{0}$, the qualified number $n_{1}$, the reseed number $n_{2}$, and the interval number $N$ as follows:

$$
\begin{aligned}
& n_{0}=n_{3}^{\prime}+2 n_{4}^{\prime}+3 n_{5}^{\prime}, \\
& n_{1}=N^{\prime}-2 n_{2}, \\
& n_{2}=n_{1}^{\prime}, \\
& N=n_{2}^{\prime}+2 n_{3}^{\prime}+3 n_{4}^{\prime}+4 n_{5}^{\prime} .
\end{aligned}
$$

The following were the formulas to calculate the reseed rate $D$, leakage rate $M$, and qualified rate $A$ :

$$
\begin{aligned}
D & =\frac{n_{2}}{N} \times 100, \\
M & =\frac{n_{0}}{N} \times 100, \\
A & =\frac{n_{1}}{N} \times 100 .
\end{aligned}
$$

Table 8 was the calculation result of the rates under different speed.

From Table 8, it could be concluded that the qualified rates under different speed were all greater than $93 \%$.

\section{Summary}

Through the above experiments, the results could verify the performance of the wheat precision seeding robot in the actual work environment. But there were differences under the different speed. And the speed was the main factor in the wheat precision seeding. 
TABLE 5: Measured data at speed of $0.7 \mathrm{~m} / \mathrm{s}$.

\begin{tabular}{cccccccccc}
\hline \multicolumn{10}{c}{ 100 adjacent seed spaces at speed of 0.7 m/s (cm) } \\
\hline 6.1 & 7.7 & 7.9 & 6.8 & 5.9 & 5.8 & 3.9 & 7.2 & 6.0 & 7.0 \\
6.5 & 6.1 & 14.8 & 5.9 & 5.6 & 4.8 & 5.0 & 6.4 & 5.6 & 4.8 \\
5.0 & 5.7 & 7.4 & 5.6 & 5.6 & 3.0 & 6.8 & 8.0 & 0.5 & 3.0 \\
4.9 & 5.8 & 6.1 & 7.2 & 4.8 & 6.2 & 15.9 & 8.7 & 6.8 & 8.0 \\
6.5 & 6.2 & 5.5 & 6.0 & 6.4 & 7.3 & 7.6 & 8.9 & 5.4 & 6.8 \\
6.7 & 7.0 & 5.9 & 8.1 & 6.5 & 8.5 & 8.4 & 6.4 & 9.0 & 3.9 \\
5.0 & 6.4 & 7.4 & 9.2 & 6.0 & 6.3 & 8.0 & 5.8 & 8.4 & 6.5 \\
4.4 & 6.0 & 4.6 & 8.4 & 7.2 & 6.4 & 7.4 & 6.0 & 8.9 & 5.4 \\
6.8 & 9.3 & 5.2 & 6.0 & 8.1 & 6.0 & 4.6 & 6.5 & 7.2 & 6.0 \\
6.0 & 9.0 & 3.9 & 5.4 & 5.4 & 9.3 & 5.2 & 7.5 & 8.6 & 5.4 \\
\hline
\end{tabular}

TABLE 6: Measured data at speed of $0.9 \mathrm{~m} / \mathrm{s}$.

\begin{tabular}{llllllllll}
\hline \multicolumn{10}{c}{ 100 adjacent seed spaces at speed of $0.9 \mathrm{~m} / \mathrm{s}(\mathrm{cm})$} \\
\hline 6.4 & 8.4 & 6.5 & 6.6 & 7.6 & 6.8 & 5.8 & 7.9 & 5.0 & 6.6 \\
6.2 & 8.9 & 5.4 & 6.8 & 5.7 & 6.0 & 6.4 & 6.5 & 4.0 & 6.8 \\
6.2 & 7.2 & 6.0 & 8.0 & 3.8 & 7.4 & 9.2 & 7.2 & 7.0 & 6.0 \\
6.3 & 5.9 & 5.8 & 7.5 & 6.5 & 4.6 & 8.4 & 5.9 & 7.3 & 8.1 \\
7.0 & 6.0 & 7.6 & 7.3 & 7.1 & 16.7 & 6.5 & 6.0 & 4.5 & 7.9 \\
7.3 & 1.0 & 5.1 & 8.4 & 8.4 & 9.0 & 7.6 & 8.5 & 8.1 & 5.6 \\
4.5 & 7.9 & 6.3 & 9.1 & 6.3 & 8.0 & 5.1 & 7.9 & 5.1 & 8.4 \\
8.1 & 5.6 & 4.8 & 7.0 & 5.1 & 5.5 & 6.3 & 8.1 & 6.3 & 9.0 \\
7.5 & 6.1 & 2.0 & 6.8 & 3.5 & 5.9 & 4.8 & 5.9 & 6.7 & 7.8 \\
6.5 & 8.0 & 5.9 & 8.4 & 6.1 & 7.4 & 6.0 & 6.9 & 6.1 & 6.8 \\
\hline
\end{tabular}

TABLE 7: Measured data at speed of $1.1 \mathrm{~m} / \mathrm{s}$.

\begin{tabular}{cccccccccc}
\hline \multicolumn{10}{c}{100} \\
\hline 6.0 & 5.7 & 6.9 & 6.9 & 8.9 & 8.3 & 7.5 & 8.4 & 7.2 & 6.0 \\
6.0 & 6.0 & 8.0 & 7.9 & 6.0 & 9.0 & 5.8 & 6.0 & 8.1 & 7.4 \\
5.4 & 6.8 & 9.2 & 9.4 & 7.0 & 8.0 & 4.6 & 5.4 & 5.4 & 5.4 \\
4.9 & 6.3 & 5.4 & 5.6 & 7.5 & 6.1 & 6.7 & 6.5 & 7.0 & 6.6 \\
7.3 & 5.1 & 5.0 & 6.0 & 6.8 & 6.4 & 5.0 & 3.4 & 8.4 & 6.8 \\
6.5 & 8.0 & 5.8 & 4.7 & 6.0 & 8.1 & 6.0 & 4.6 & 6.5 & 7.6 \\
7.8 & 7.4 & 6.0 & 9.8 & 5.4 & 5.4 & 16.3 & 5.2 & 7.5 & 7.6 \\
7.2 & 4.6 & 6.5 & 1.2 & 6.6 & 7.6 & 6.8 & 5.8 & 15.5 & 5.2 \\
5.2 & 5.2 & 7.5 & 6.0 & 6.9 & 8.6 & 6.0 & 8.0 & 5.4 & 6.8 \\
6.2 & 5.8 & 8.1 & 5.4 & 5.4 & 5.4 & 5.6 & 6.3 & 6.2 & 7.0 \\
\hline
\end{tabular}

TABLE 8: Results under different speed.

\begin{tabular}{lccc}
\hline $\begin{array}{l}\text { Speed } \\
(\mathrm{m} / \mathrm{s})\end{array}$ & $\begin{array}{c}\text { Qualified } \\
\text { rate }(\%)\end{array}$ & $\begin{array}{c}\text { Reseed } \\
\text { rate }(\%)\end{array}$ & $\begin{array}{c}\text { Leakage } \\
\text { rate }(\%)\end{array}$ \\
\hline 0.7 & 94.81 & 0.96 & 4.80 \\
0.9 & 95.15 & 0.97 & 3.88 \\
1.1 & 93.33 & 0.95 & 5.71 \\
\hline
\end{tabular}

\section{Conflict of Interests}

The authors declare that there is no conflict of interests regarding the publication of this paper.

\section{References}

[1] D. Oetomo, J. Billingsley, and J. F. Reid, "Editorial: agricultural robotics," Journal of Field Robotics, vol. 26, no. 6-7, pp. 501-503, 2009.

[2] D. Oetomo and J. Billingsley, "Editorial: special issue on agricultural robotics," Intelligent Service Robotics, vol. 3, no. 4, pp. 207-208, 2010.

[3] L. Emmi, M. Gonzalez-De-Soto, G. Pajares, and P. GonzalezDe-Santos, "New trends in robotics for agriculture: integration and assessment of a real fleet of robots," The Scientific World Journal, vol. 2014, Article ID 404059, 21 pages, 2014.

[4] S. Shibusawa, "Community-based precision farming for small farm agriculture," in Proceedings of the 6th International Conference on Precision Agriculture [CD-ROM], Minneapolis, Minn, USA, 2002

[5] J. F. Reid, Q. Zhang, N. Noguchi, and M. Dickson, "Agricultural automatic guidance research in North America," Computers and Electronics in Agriculture, vol. 25, no. 1-2, pp. 155-167, 2000.

[6] T. Torii, "Research in autonomous agriculture vehicles in Japan," Computers and Electronics in Agriculture, vol. 25, no. 1-2, pp. 133-153, 2000.

[7] J. Ji and Z. Zheng, "Current situation and development tendency of agriculture robot," Journal of Agricultural Mechanization Research, no. 2, pp. 1-9, 2014.

[8] Z. Yi and Z. Hu, "General situation and development of agricultural robot," Jiangsu Agricultural Sciences, no. 2, pp. 390393, 2010.

[9] Y. Songlie, Theory and Practice on Chinese Wheat Cultivation, Shanghai Science and Technology Press, Shanghai, China, 2006.

[10] F. L. Willrodt, "Steering Attachment for Tractors," US Patent no. 1506706, 1924.

[11] S. Sakai, M. Iida, K. Osuka, and M. Umeda, "Design and control of a heavy material handling manipulator for agricultural robots," Autonomous Robots, vol. 25, no. 3, pp. 189-204, 2008.

[12] H. G. Tanner, K. J. Kyriakopoulos, and N. I. Krikelis, "Advanced agricultural robots: kinematics and dynamics of multiple mobile manipulators handling non-rigid material," Computers and Electronics in Agriculture, vol. 31, no. 1, pp. 91-105, 2001.

[13] T. Bakker, K. van Asselt, J. Bontsema, J. Müller, and G. van Straten, "Autonomous navigation using a robot platform in a sugar beet field," Biosystems Engineering, vol. 109, no. 4, pp. 357368, 2011.

[14] S. M. Pedersen, S. Fountas, H. Have, and B. S. Blackmore, "Agricultural robots-system analysis and economic feasibility," Precision Agriculture, vol. 7, no. 4, pp. 295-308, 2006.

[15] D. C. Slaughter, D. K. Giles, and D. Downey, "Autonomous robotic weed control systems: a review," Computers and Electronics in Agriculture, vol. 61, no. 1, pp. 63-78, 2008.

[16] K. Iagnemma, A. Rzepniewski, S. Dubowsky, and P. Schenker, "Control of robotic vehicles with actively articulated suspensions in rough terrain," Autonomous Robots, vol. 14, no. 1, pp. 5-16, 2003.

[17] Z. Tao, L. Jun, and Z. Liangrong, "Simple controller design for wheeled mobile robot," Journal of Yanshan University, vol. 32, no. 4, pp. 316-318, 2008. 
[18] S. L. Dong, "Study on the pickup performance of new-type wheat seed-metering," Journal of Anhui Agricultural Sciences, vol. 39, no. 18, pp. 11215-11216, 2011.

[19] Z. B. Barut and A. Özmerzi, "Effect of different operating parameters on seed holding in the single seed metering unit of a pneumatic planter," Turkish Journal of Agriculture and Forestry, vol. 28, no. 6, pp. 435-441, 2004.

[20] J. J. Far, S. K. Upadhyaya, and S. Shafii, "Development and field evaluation of a hydropneumatic planter for primed vegetable seeds," Transactions of the American Society of Agricultural Engineers, vol. 37, no. 4, pp. 1069-1075, 1994.

[21] P. Guarella, A. Pellerano, and S. Pascuzzi, "Experimental and theoretical performance of a vacuum seeder nozzle for vegetable seeds," Journal of Agricultural Engineering Research, vol. 64, no. 1, pp. 29-36, 1996.

[22] D. Karayel, Z. B. Barut, and A. Özmerzi, "Mathematical modeling of vacuum pressure on a precision seeder," Biosystems Engineering, vol. 87, no. 4, pp. 437-444, 2004.

[23] C. Yue and X. Guanghua, The Design Method of Scientific Research and Engineering Experiment, Wuhan University of Technology Press, Wuhan, China, 2005. 

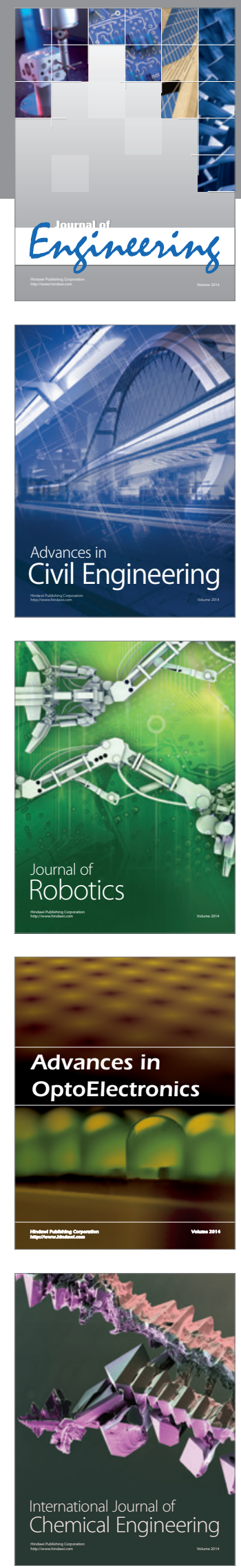

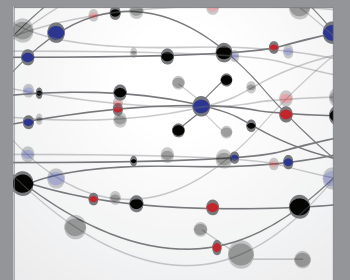

The Scientific World Journal
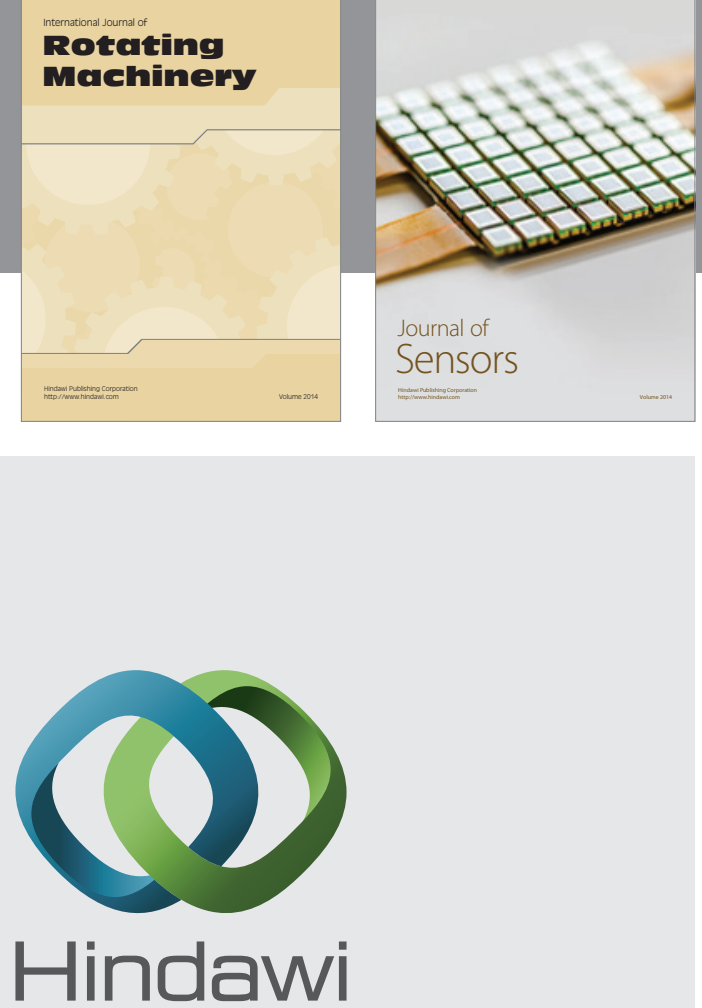

Submit your manuscripts at http://www.hindawi.com
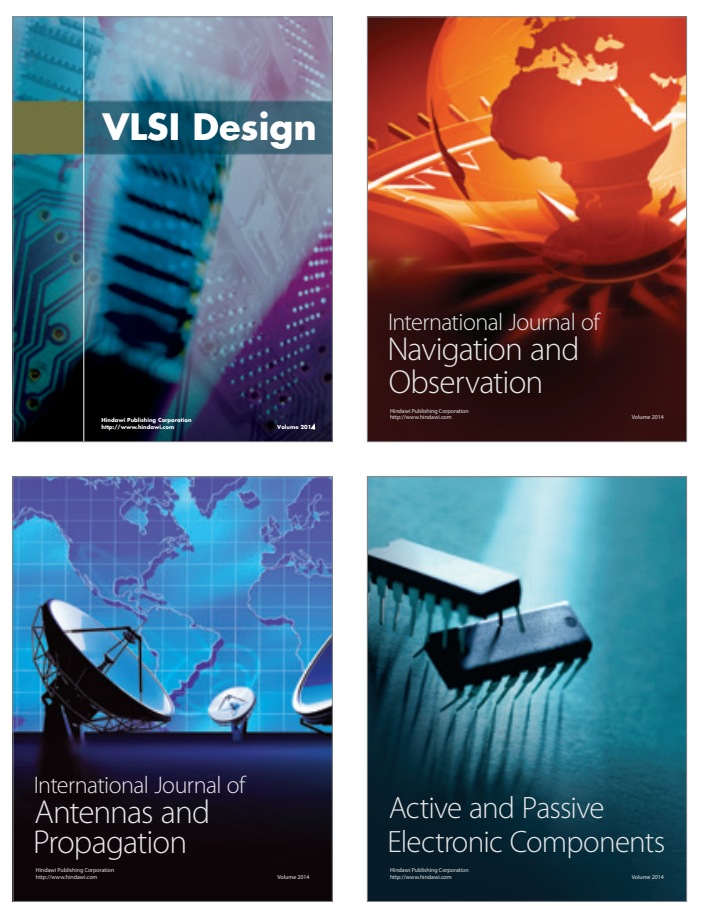
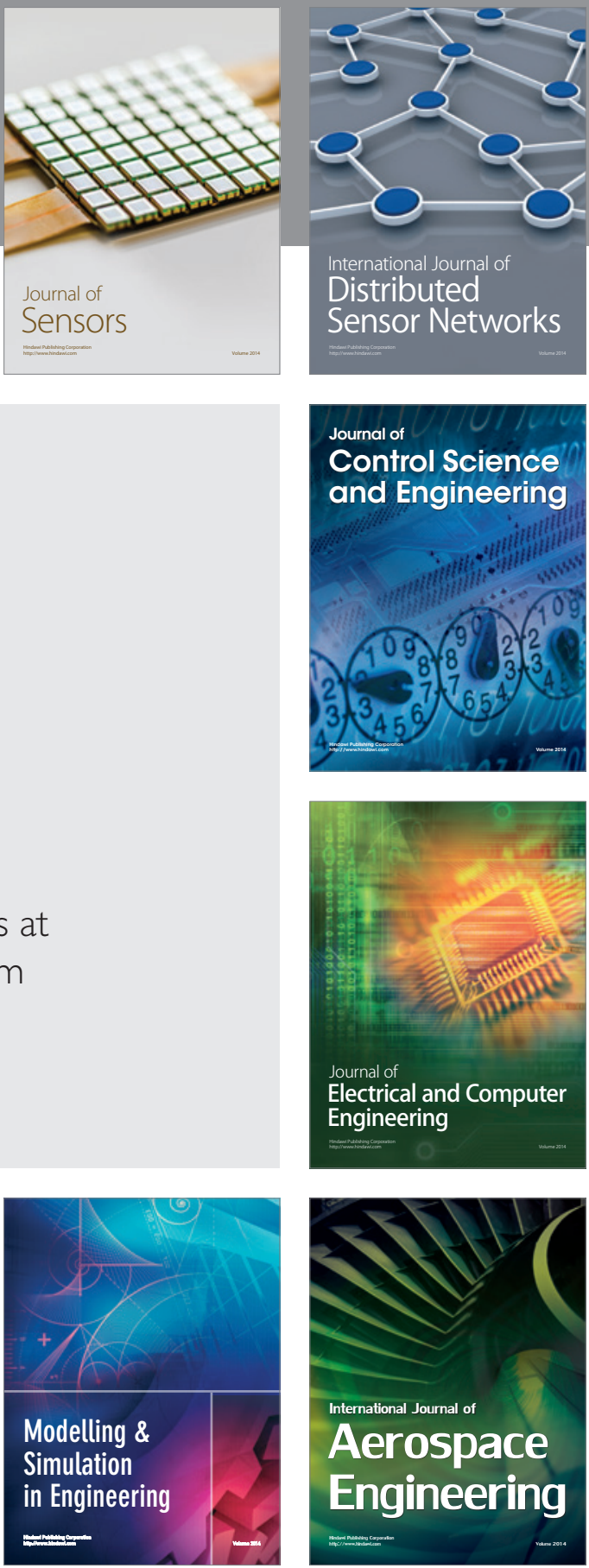

Journal of

Control Science

and Engineering
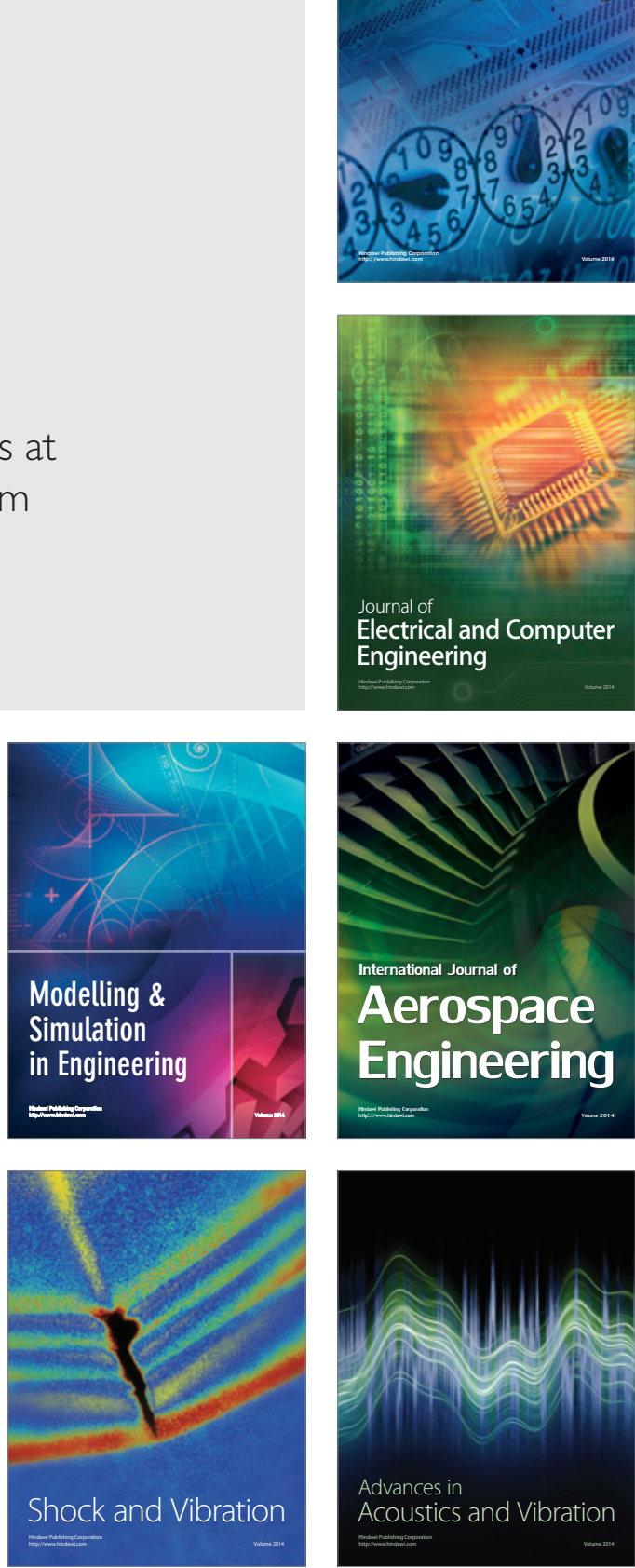